\title{
The prediction and mapping of coastal flood risk associated with storm surge events and long-term sea level changes
}

\author{
T. Webster \& D. Stiff \\ Applied Geomatics Research Group, Centre of Geographic Sciences, \\ Nova Scotia Community College, Canada
}

\begin{abstract}
Non-specialized researchers, emergency management personnel, and land use planners require an accurate, inexpensive method to determine and map risk associated with storm surge events and long-term sea level rise associated with climate change. This study has developed new geomatics tools to map flood risk and has been applied to a case study area in the Minas Basin, Bay of Fundy, Canada. The Minas Basin has the highest recorded tides in the world and agricultural and rural development has been established along the coastline behind dykes, which are up to $3 \mathrm{~m}$ high. A newly developed ArcGIS tool, Storm flood, in conjunction with a newly developed software program Water Modeler, and a LiDAR derived Digital Elevation Model (DEM) were used together to map coastal flood risk. Storm flood uses the LiDAR derived DEM as a base and calculates the area of inundation assuming a still water level. The tool also ensures that connectivity is enforced so that the storm surge waters are sourced from the ocean and that low-lying inland areas that do not have free connection to the ocean are not inundated. This "connectivity check" overcomes a limitation of some standard third party hydrologic modelling tools such as $H E C-R A S$ that do not check for connectivity to source waters that in some cases cause the resultant inundation maps to be incorrect when imported into a GIS environment. The recurrence intervals of a given water level are determined using Water Modeler by using the time series of local tide gauge records. Relative changes in sea level associated eustatic conditions, from climate change, and local crustal motion can be incorporated into the software to calculate the return period of water levels in the future under variable conditions
\end{abstract}

Keywords: storm surge, flood risk, LiDAR, GIS, Water Modeler, return periods. 


\section{Introduction}

Many coastal communities in Canada and around the world are at risk due to flooding from storm-surge events. Past studies have examined the vulnerability of Maritime Canada to coastal flooding from climate change [1,2]. A stormsurge is an increase in the ocean water level above what is expected from the normal tidal level that can be predicted from astronomical observations and is most often caused by the winds and low pressure of atmospheric storms. Global sea-level rise, as predicted by climate change models, will increase the risk due to storm surges making more coastal areas vulnerable to flooding (Church et al [3]). A set of tools that can be applied within a Geographic Information System (GIS) have been developed to assist coastal municipalities identify areas at risk from coastal flooding as part of this project.

Communities around the Bay of Fundy, including the town of Wolfville in the Minas Basin, and along the Cornwallis River estuary, are vulnerable to coastal flooding from storm-surge events (Figure 1). Some past storms of significance include the Saxby Gale of 1869 and the more recent Groundhog Day storm on Feb. 2, 1976 [4-7]. Unfortunately no local tide gauges were in place in the Minas Basin during these storms that could be used to assess the height of the stormsurge. However, water levels from the tide gauge at Saint John, New Brunswick, across the Bay of Fundy were used to determine the height of the storm surge during this event. This storm provides us with a benchmark of the flooding that can occur in the region under current water levels and climate conditions.
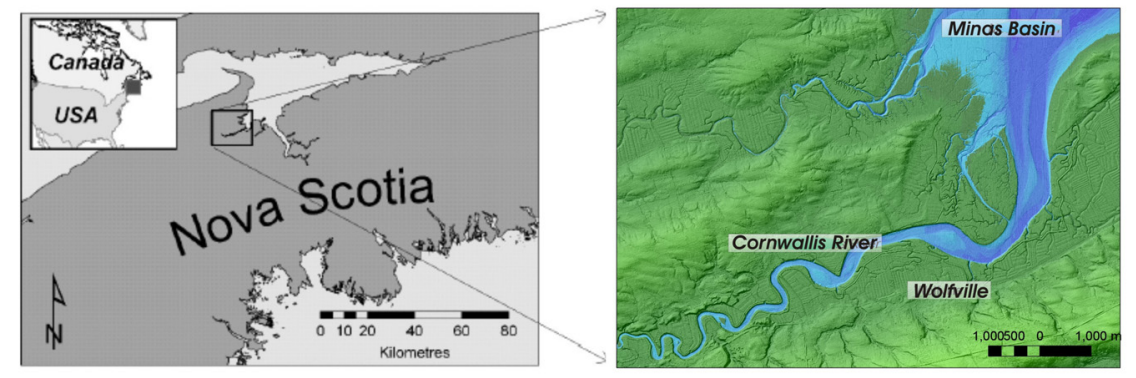

Figure 1: The study area is located in the Bay of Fundy, Canada. The Cornwallis River and much of the land around Wolfville is dyked.

LIDAR (Light Detection and Ranging) has been used to construct a highresolution digital elevation model (DEM) and build flood inundation maps for given water levels from storm surges and longer term sea-level rise. This remote sensing technique involves an aircraft equipped with a laser rangefinder that shoots pulses of light towards the earth, and by measuring the two-way travel time, determines the distance or range from the aircraft to the earth's surface. By knowing the precise location of the aircraft with GPS and the distance to the earth's surface, land elevations can be determined. LIDAR measures the earth's surface every 1-2 $\mathrm{m}$ on the ground with vertical accuracies within $\pm 0.15 \mathrm{~m}$. 
Previous studies that map possible flood inundation areas from higher than usual ocean water levels assume a still water level or flat plane parallel to the geoid $[8,9]$. This is justified in part because of the small scale of weather systems $(10 \mathrm{~s} \mathrm{~km})$ that are associated with storm surges relative to the size of coastline that has been examined. An ARC GIS script has been developed known as Storm flood that can facilitate the generation of inundation areas. The approach checks that all flooded areas have a connection to the ocean source area, thus ensuring only low-lying areas are flooded that have a hydraulic pathway connecting the ocean.

Once the water inundation areas have been determined, a new tool known as Water Modeler can be used to assign risk for a given water level based on a time series of observed water levels. We have calculated water levels for return periods based on 40 years of water level records from St. John, NB, which has one of the longest water level records (via a tide gauge) in the region. The method calculates empirical annual probabilities of exceedance of a given water level and allows a model to be constructed for the prediction of probabilities. The probability statistics are based on the "peak over threshold method".

In order to incorporate climate change effects into the model we increased the sea-level by $80 \mathrm{~cm}$ over the next 100 years, and recalculated the return periods of given water levels using Water Modeler. The relative sea-level rise estimate of $80 \mathrm{~cm}$ in the next century is a combination of global sea-level rise taken to be 50 $\mathrm{cm}$ (Church et al [3]), local crustal subsidence of $20 \mathrm{~cm}$ (Peltier [10]), and an increase in the tidal amplitude taken to be $10 \mathrm{~cm}$ (Godin [11]).

\section{Methods}

\subsection{LiDAR}

High precision LiDAR was collected of the area in May 2003 with coastal areas being collected at low tide. A $1 \mathrm{~m}$ resolution Digital Elevation Model (DEM) was created to be used for storm surge modelling. The original LiDAR points were converted from ellipsoidal heights to orthometric heights referenced to the Canadian Geodetic Vertical Datum of 1928 (CGVD28). The DEM is representative of the earth with all trees and buildings removed. As such, it can be called a 'bald earth' model. This bald earth model is useful for creating flooding models, as it does not have any false barriers created by trees that may hinder flow. The validation of the LiDAR data consists of taking surveyed ground points and comparing them against easily identifiable points on the DEM. The Nova Scotia Department of Agriculture and Fisheries had previously surveyed GPS points along several areas of the dykes, which were used for validation. The GPS points were subtracted from the DEM and any differences were then analysed. After subtraction, it was determined that there was a $10 \mathrm{~cm}$ difference between the DEM and the GPS points; therefore, $10 \mathrm{~cm}$ was added to the DEM. This corresponded to previously validated LiDAR data that was surveyed at the same time. 
The DEM created does not account for culverts or abioteaux that may run under roads and dykes. Culverts allow for the flow of water in two directions (from the ocean and to the ocean) whereas an abioteau allows for water to flow only in one direction (to the ocean). It is therefore necessary to determine where each are located to insure that proper flow is maintained between disjunct areas, for example areas separated by a road or dyke. The methodology outlined in Webster and Forbes [12] was used to construct the hydraulic pathways in the DEM. Specifically, the culverts were determined based on visual inspection and records from the Nova Scotia Department of Agriculture and Fisheries were used to determine where the culverts were located. For culverts, the stream or ditch on each side of the road were then queried to determine the elevation. A shape file was then populated with what the elevation of the water through each of the culverts would be and then rasterized based on this elevation.

\subsubsection{Storm flood GIS script}

Using the ArcMap ${ }^{\circledR}$ environment and Visual Basic Scripting, a toolbox containing a storm surge script was developed which will flood a region of a given Digital Elevation Model (DEM) based on connectivity at user specified increments. Details of the script and the downloadable code are reported in Stiff and Webster (in prep.). Due to the nature of the script and the large number of levels to be created it was deemed very important that file sizes remain as small as possible. As such it was decided that a) tiff files would be in 16 bit signed (integer) format, and $b$ ) the resolution of the final files could be varied depending on the final viewing resolution. It was also required that shapefiles of each level be created with a field specifying the water level in metres. Finally, file names of all the same length and structure (especially for the tiff files) were required so that they could be easily interpreted in other programs.

\subsubsection{Ocean point}

This is the point from which the script determines if the flooded area is attached to the ocean or is simply below sea level. This comes in to play in such situations as areas behind dykes or other low lying areas, which are below sea level but would not be flooded due to simple sea level rise. Conversely, multiple points can be used in situations were the flooded area is split (for example the DEM does not cover all of the shoreline) and two regions will be flooding at the same time. It is important that at least one point be somewhere that will be flooded at all times and is never 'dry'.

\subsubsection{Low Level}

This is the lowest flood level that will be created. To flood just one level, set this to be the same as the high level.

\subsubsection{High level}

This is the highest flood level that will be created. To flood just one level, set this to be the same as the low level. 


\subsubsection{Increment}

This is the increment that will be used to go between the low level and the high level. For low and high levels that are the same this can be any number (e.g. $0.1 \mathrm{~m})$.

\subsubsection{Output folder}

This is the folder in which your storm flood will be located. It is important that this folder be free of any temporary files that may have been created while the script was running. It is also important that there are not any other files of flood levels that will be created.

\subsubsection{Output tiff resolution}

The output tiff resolution is primarily based on the resolution of the image files that you are going to use for display purposes. This resolution does not affect the connectivity of any channels that you may have that are less then the resolution specified here. Connectivity is based on the resolution of the DEM.

\subsection{Water Modeler}

Coastal flooding return statistics can be generated by looking at long term water level records. For coastal areas these records are collected by tide gauges and in Canada this is the jurisdiction of the Canadian Hydrographic Service (CHS) of the Department of Fisheries and Oceans (DFO). The coastal water level records are available from DFO's Marine Environmental Data Service on the internet (http://www.meds-sdmm.dfo-mpo.gc.ca/meds/Home_e.htm). These water level records are referenced to local harbours and chart datum. These represent the observed water levels and the storm surge can be calculated by subtracting the predicted water levels (http://tbone.biol.sc.edu/tide/) and calculating the residuals.

The return periods and probabilities of a given water level or storm surge can be calculated from these time series of water levels. The methods used to calculate the statistics vary and can be complex. Without the statistical software, end users would obtain information from a set of flood level return periods curves. Water Modeler allows observed water level records to be analysed and probabilities and return periods to be calculated. The water levels are converted from chart datum (CD) to orthometric heights by applying an offset. In the case of St. John, the difference between CD and CGVD28 is $4.19 \mathrm{~m}$. The approach taken calculates empirical annual probabilities of exceedance of a given water level, and allows a model to be constructed for the prediction of probabilities. Alternatively a given water level, such as that associated with the Groundhog Day storm, can be used and a cumulative probability curve be constructed where the $\mathrm{X}$-axis represents the return period in years and the $\mathrm{Y}$-axis represents the probability from $0-1$. For a given return period the probability of that water level occurring can be read from the curve. The probability of the water level occurring increases as the return period increases. Other information that land use planners often seek is to determine the water level of a storm with a 10 year return period, or the 100 year storm event for example. The data can be presented 
in a format where the water level is on the Y-axis and the return period is on the $\mathrm{X}$-axis, allowing any return period water level to be calculated. Any of these statistics can be recalculated with relative sea-level changes incorporated, to simulate possible climate change effects. For example, the water level - return period graph is recalculated with a relative sea level rise of $80 \mathrm{~cm}$ during the next 100 years (Figure 2).

For the case study area, Webster et al [9] reported storm surge levels of $0.6 \mathrm{~m}$ with a 20 year return period, and $1.2 \mathrm{~m}$ with a 100 year return period. However, no intermediate water levels or return periods were published, nor is climate change and changes in relative sea-level accounted for. The case study area is located approximately $120 \mathrm{~km}$ to the northeast of the nearest long term tide gauge (St. John, New Brunswick). As a result the orthometric heights of water levels calculated at St. John are not directly transferable to orthometric heights in the Minas Basin.

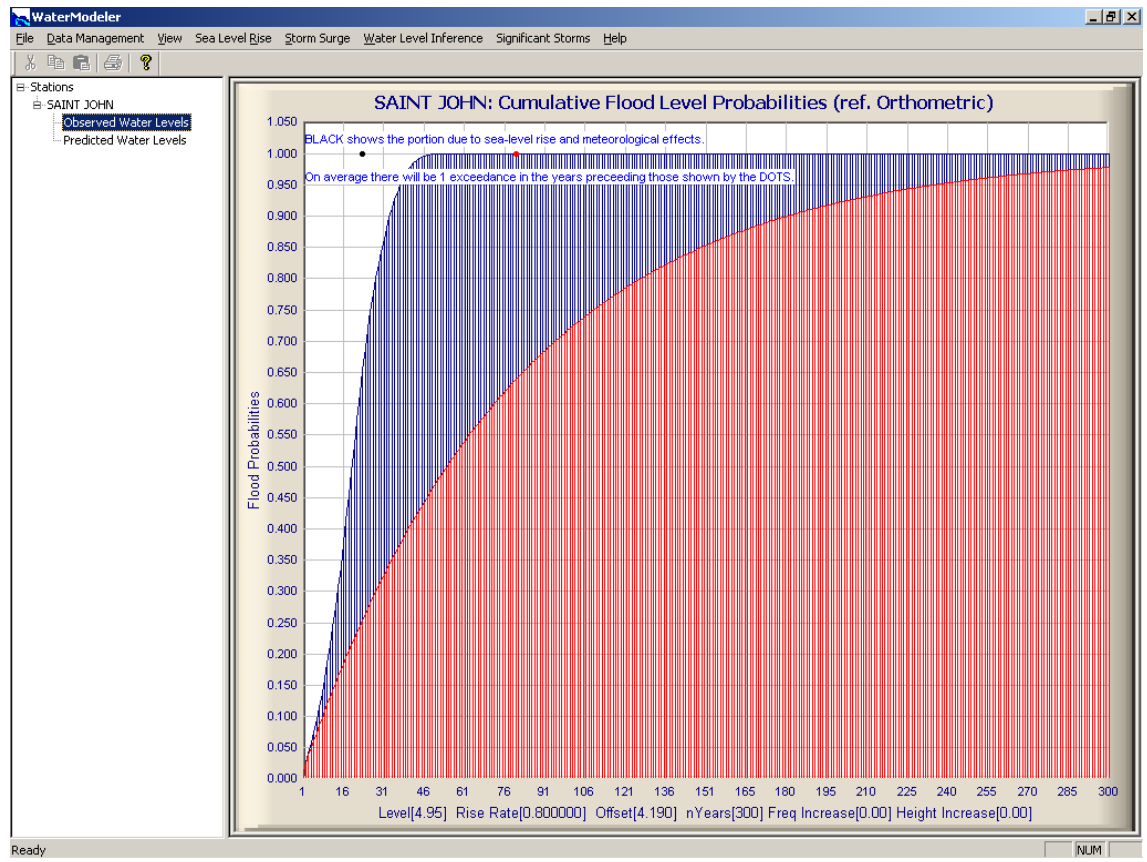

Figure 2: The empirical annual probabilities of exceedance of a given water level as calculated in Water Modeler. The light grey line represent no rise in sea level, the dark grey represents a sea level rise rate of $80 \mathrm{~cm}$ in 100 years.

As one moves eastward in the Bay of Fundy, tidal range increases by $6 \mathrm{~m}$ from St. John to the Minas Basin. In this study we test if results obtained from Water Modeler for the St. John tide gauge records are transferable to the Minas Basin. We use the variation in the geoid as defined by the relationship between 
chart datum and the mean water level at the two sites. The difference in the geoid between St. John and Minas Basin is applied to the St. John water level of the Groundhog Day storm. To evaluate if this method, we compare the published 100 year storm surge level projected onto high tide water level (HHWLT) with the geoid-adjusted Groundhog Day storm event.

\section{Results}

The LiDAR DEM was used along with Storm Flood to build inundation maps for the Cornwallis River in the Minas Basin for the published one in 20 year and one in 100 year storm surge events. The DEM elevations are referenced to CGVD28, and the thus the tide levels are converted from local chart datum to orthometric heights above CGVD28. As a result, the storm surge was added to a large spring tide (HHWLT) resulting in a total water level of $7.23 \mathrm{~m}$ and $7.83 \mathrm{~m} \mathrm{CGVD28}$ for the 20 and 100 year events (Figure 3).

The CD-geoid relationship for St. John where we have a time series of water level records is $4.19 \mathrm{~m}$. The total water level of the Groundhog Day storm in St. John was $4.95 \mathrm{~m}$ orthometric. The relationship for the Minas Basin is $7.23 \mathrm{~m}$, thus a difference from St. John of $3.04 \mathrm{~m}$. Assuming no amplification of the storm surge from St. John to the Minas Basin, the calculated total water level of the Groundhog Day storm in the Minas Basin is $7.99 \mathrm{~m}$ orthometric.

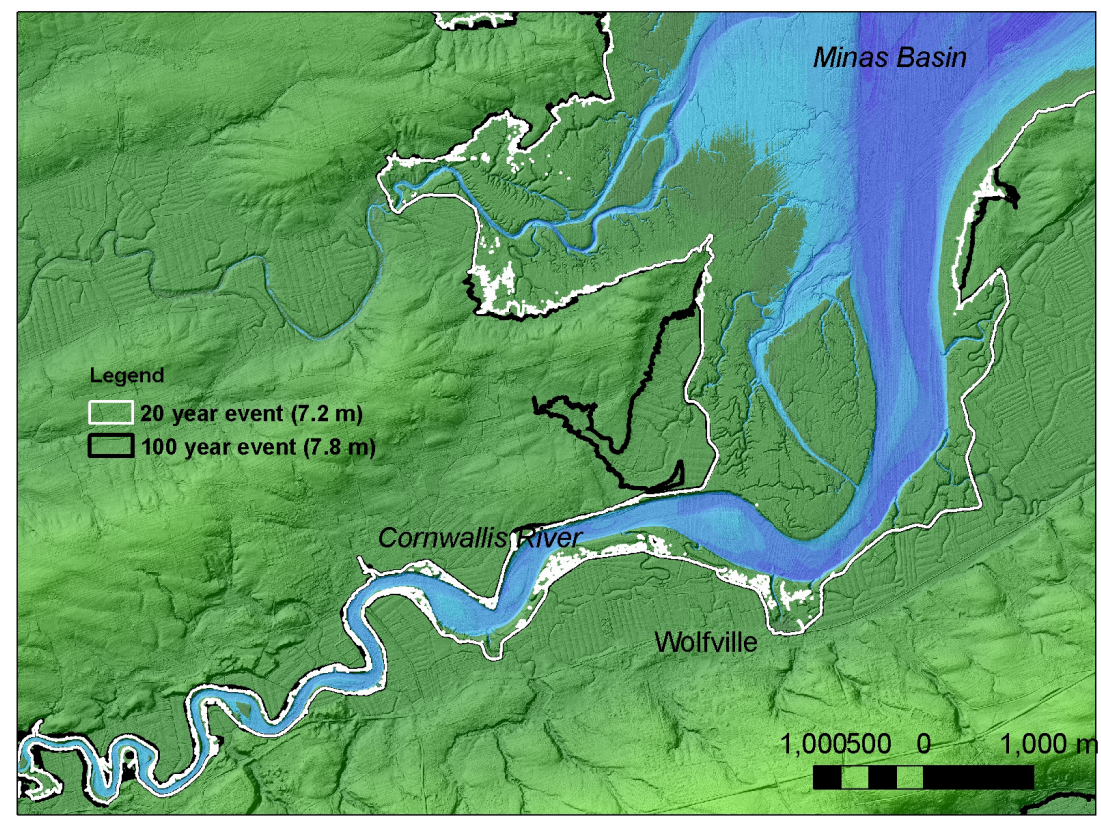

Figure 3: The 20 and 100 year return events in the Minas Basin, not taking into account sea level rise. 
The results of analysing the water level records for St. John in Water Modeler indicate the Groundhog Day storm has a return period of 121 years with a probability of 1 under current sea level rise conditions, and an average return period of 43 years with a probability of 0.63 . The Groundhog Day storm level $(7.99 \mathrm{~m})$ and return period (121 years) as calculated from the St. John water level record is in general agreement with the previously published storm surge level occurring at high tide ( $7.83 \mathrm{~m}$ with a 100 year return period).

Water Modeler was also used to recalculate the statistics and project the potential relative sea-level rise of $0.8 \mathrm{~m}$ in the next century resulting from climate change and local crustal and tidal conditions. The average return period of the Groundhog Day storm (0.63 probability) reduces to 23 years and the absolute probability (1.0) changes to 55 years. Thus the same storm in 100 years could reach a water level of approximately $8.8 \mathrm{~m}$ (Figure 4). At this water level the dykes protecting the low-lying agricultural lands are breached and the ocean significantly extends landward.

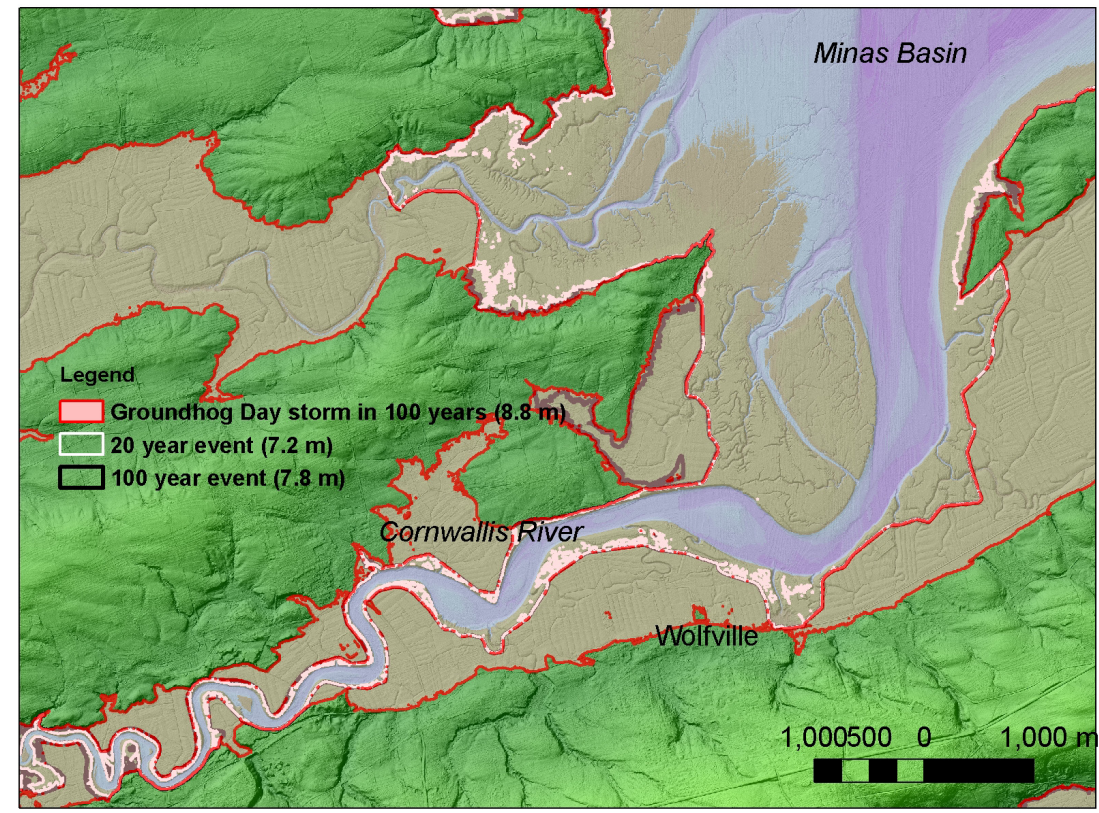

Figure 4: The flood risk associated with a storm equivalent to the Groundhog Day storm in 100 years. Almost all of the dykes are overtopped.

\section{Conclusion}

The combination of GIS tools (Storm Flood) and statistical analysis tools (Water Modeler) combined with high-resolution LiDAR DEMs allow coastal communities to plan for possible storm surge events. The Storm Flood tool 
allows inundation maps to be quickly constructed at detailed intervals (e.g. 0.1 m) ensuring connection between the low-lying areas and ocean. The risk of inundation can be determined by using the Water Modeler if a time series of water level records are available. Ideally the water level time series is for the same location as the inundation study, however we have demonstrated that results can be transferred to other locations if the local conditions are similar. Since the Groundhog Day storm is calculated to be close to a 100 year event using Water Modeler, it was used to compare with the published 100 year storm surge levels. Both methods produced similar results although the Water Modeler allows much more information to be extracted, such as the return periods of other water levels and the imposition of relative sea level changes. A relative sea level change of $80 \mathrm{~cm}$ in the next century is expected in this region and based on our mapping, risk to local coastal communities to flooding is very high.

\section{References}

[1] McCulloch, M.M., Forbes, D.L., Shaw, R.W. \& the CCAF A041 Scientific Team. 2002. Coastal Impacts of Climate Change and Sea-Level Rise on Prince Edward Island. Geological Survey of Canada. Open File 4261.

[2] Daigle, R. \& Project Research Team. 2006. Impacts of sea level rise and climate change on the coastal zone of southeastern New Brunswick/ Impacts de l'élévation du niveau de la mer et du changement climatique sur la zone côtière du sud-est du Nouveau-Brunswick. Environment Canada, 611 pp. (also on CD-ROM and on-line at http://atlanticweb1.ns.ec.gc.ca/slr/).

[3] Church, J.A., Gregory, J.M., Huybrechts, P., Kuhn, M., Lambeck, K., Nhuan, M.T., Qin, D. \& Woodworth, P.L., Changes in Sea Level. Climate Change 2001: The Scientific Basis. Contribution of Working Group 1 to the Third Assessment Report of the Intergovernmental Panel on Climate Change [Houghton, J.T., Y. Ding, D.J. Griggs, M. Noguer, P.J. van der Linden, X. Dai, K. Maskell, and C.A. Johnson (eds.)], Tech. Rep. 881pp, 2001.

[4] MacDonald, A. Winds of Change Severe Weather in The Annapolis Valley, Unpublished Thesis, 2006, Bachelor of Arts with Honours in History, Acadia University, Feb. 2006.

[5] Abraham, J., Parkes, G., \& Bowyer, P., The transition of the "Saxby Gale" into an extratropical storm, $23^{\text {rd }}$ Conference on Hurricanes and Tropical Meteorology, American Meteorological Society, Dallas, Tx. pp. 795-798, 1999

[6] Desplanque, C. \& Mossman, D., Storm Tides of the Fundy. The Geographical Review, 89, pp. 23-33, 1999

[7] Parkes, G., Ketch, L., \& O'Reilly, C., Storm surge events in the Maritimes, Procedures of the Canadian Coastal Conference, pp. 115-129, 1997.

[8] Webster, T.L., Forbes, D.L., Dickie, S., \& Shreenan, R., Using topographic lidar to map flood risk from storm-surge events for Charlottetown, Prince 
Edward Island, Canada. Canadian Journal of Remote Sensing, 30(1), pp. 54-76, 2004.

[9] Webster, T.L., Forbes, D.L., MacKinnon, E. \& Roberts, D., Floodrisk mapping for storm-surge events and sea-level rise in Southeast New Brunswick. Canadian Journal of Remote Sensing, 32(2), pp. 194-211, 2006

[10] Peltier, W.R., Global glacial isostasy and the surface of the ice-age earth: The ice-5G (VM2) model and Grace, Annual Review of Earth and Planetary Sciences, (32), pp. 111-149, 2004.

[11] Godin G., Possibility of rapid changes in the tide of the Bay of Fundy, based on a scrutiny of the records from Saint John. Continental Shelf Research, (12), 1992.

[12] Webster, T.L. \& Forbes, D.L., Airborne laser altimetry for predictive modelling of coastal storm-surge flooding. Remote Sensing of Aquatic Ecosystem Processes, Science and Management Applications, eds. LeDrew, E. \& Richardson, L., pp. 157-180. 2006 